\title{
Implementation of an environmental education course to improve pre-service elementary teachers' environmental literacy and self-efficacy beliefs
}

\section{Deniz Saribas, Zerrin Doganca Kucuk \& Hamide Ertepinar}

To cite this article: Deniz Saribas, Zerrin Doganca Kucuk \& Hamide Ertepinar (2017) Implementation of an environmental education course to improve pre-service elementary teachers' environmental literacy and self-efficacy beliefs, International Research in Geographical and Environmental Education, 26:4, 311-326, DOI: 10.1080/10382046.2016.1262512

To link to this article: https://doi.org/10.1080/10382046.2016.1262512

曲 Published online: 14 Dec 2016.

Submit your article to this journal $\pi$

ఋ Article views: 381

View related articles

View Crossmark data \lceil

Citing articles: 4 View citing articles $\longleftarrow$ 


\title{
Implementation of an environmental education course to improve pre-service elementary teachers' environmental literacy and self-efficacy beliefs
}

\author{
Deniz Saribas ${ }^{\mathrm{a}}$, Zerrin Doganca Kucuk ${ }^{\mathrm{b}}$ and Hamide Ertepinar ${ }^{\mathrm{c}}$ \\ aPreschool Teacher Education Department, Faculty of Education, Istanbul Aydin University, Istanbul, Turkey; \\ ${ }^{\mathrm{b}}$ Primary Education Department, Faculty of Education, Bogazici University, Istanbul, Turkey; ${ }^{\text {Primary }}$ \\ Education Department, Faculty of Education, Istanbul Aydin University, Istanbul, Turkey
}

\begin{abstract}
This study aims to investigate effects of a treatment implemented in an environmental education course on pre-service elementary teachers' environmental literacy and self-efficacy beliefs. During the course, 58 participants were informed about basic concepts of ecology, went to climate change exhibition, and prepared presentations and reflections about selected environmental problems. Scale of Self-Efficacy Belief towards Environmental Education and Scale of Environmental Literacy were used as preand post-tests. The participants' reflections were analyzed to provide a deeper insight of their understanding of climate change. Results showed that the participants' environmental attitudes, perception of environmental uses, and self-efficacy beliefs increased significantly, although there was no significant change in their environmental knowledge and concern at the end of the course. Analyses of their reflections indicated an improvement in understanding climate change. The article includes suggestions for overcoming limitations of the study.
\end{abstract}

\section{KEYWORDS}

Environmental literacy; selfefficacy belief; environmental education; pre-service elementary teachers; understanding of climate change

\section{Introduction}

The importance of educating environmentally literate citizens is emphasized in literature (Hodson, 2003; UNESCO-UNEP, 1987). Capra (1996) discusses importance of "ecoliteracy" defined as "understanding basic principles of organization of ecosystems and using those principles for creating sustainable human communities" (p. 3). Tuncer et al. (2009) identified four components of environmental literacy (EL): environmental knowledge (EK), environmental attitudes, perception of environmental uses, and environmental concern. They adapted an instrument to assess 684 pre-service teachers' EL and examined the relationship between participants' EK, attitude, uses, and concerns. They found a correlation between EK and environmental concern as well as between EK and perception of environmental use. Their results showed that environmental attitudes and perception of environmental use were highly correlated, while there were also significant relationships 
between environmental attitudes and concern, and between environmental concern and use.

Roth (1992) showed that EL requires having affection for the environment, such as emotional bonding and sensitivity toward nature. Alp, Ertepinar, Tekkaya, and Yilmaz (2008) showed that such affective components have a significant impact on elementary school students' environmental friendly behaviors. According to Roth (1992), self-efficacy belief (SEB) is one of the components of affective domain of EL. Thus, in order to produce environmentally literate students, there should be more educational efforts to increase inservice and pre-service teachers' SEBs related to environmental education (EE). Petegem, Blieck, Imbrecht, and Hout (2005) emphasized integration of EE courses in teacher training programs to guarantee inclusion of environmental topics in teaching. They strongly supported development of affective components toward nature together with learning about ecology and geography in these courses. In addition to teaching about environmental problems, sustainability, and developing environmental awareness, Yavetz, Goldman, and Péer (2009) mentioned about teaching relevant pedagogies in teacher training EE courses to handle discussions about environmental dilemmas within classrooms.

There have been some research works examining EL in Turkey. Tuncer et al. (2009) assessed pre-service teachers' EL and discovered that pre-service teachers' EK is positively related to their EL. Erdogan and Ok (2011) made a nationwide study in which they investigated fifth-graders' level of EL. They found that $61 \%$ of the students have a moderate-level EL while $30 \%$ showed high-level EL and only $0.9 \%$ have low-level EL. Erdoğan, Marcinkowski, and Ok (2009) analyzed the content of such research and concluded that more exploratory and descriptive studies are needed for a better understanding of EL in Turkey.

West (2015) criticized the EE literature about limited research on teaching programs regarding understanding of various environmental problems. For this research, climate change (CC) was selected as a major environmental problem to study based on its complex nature (Sterman \& Sweeney, 2002) and various misconceptions (Boon, 2010; Kilınç, Stanissteet, \& Boyes, 2008; Papadimitriou, 2004). Moreover, Özdem, Dal, Öztürk, Sönmez, and Alper (2014) studied on affective aspects about CC and investigated seventh-graders' general environmental concerns, experiences, beliefs, attitudes, values, and actions relating to CC. They found that students care about CC but they do not believe that they can do anything about it. Hence, investigating alternative methods to improve understanding of CC and to evoke more affective components toward CC is a challenge at any stages of education.

By taking into account the specified drawbacks of EE literature, this study examines pre-service teachers' EL and SEB during an EE course in a teacher training program. Besides, the research provides a deep insight of pre-service teachers' general understanding of CC by the analysis of their reflections before and after visiting a CC exhibition within the EE course. Considering the direct or indirect relatedness of all environmental problems to CC, this study specifically focused on the participants' understanding of CC.

\section{Self-efficacy beliefs related to environmental education}

Enhancement of pre-service teachers' EL is an important objective since they will educate future generations. In this respect, their SEB related to EE is also worth studying. Bandura (1986) pointed out the effect of SEB on individuals' activities, efforts, and persistence. He 
found that those who have high SEB believe that they will succeed with sufficient time, effort, and persistence. Bandura (1986) explained that "Perceived self-efficacy is defined as people's judgments of their capabilities to organize and execute courses of action required to attain designated types of performances" (p. 391). Individuals who have SEB are likely to work hard on a task, and when they encounter difficulties they persevere longer than those who have self-doubts. Teachers holding low SEB tend to focus their attention on negative aspects of their classrooms and are less likely to be effective (Pintrich \& Schunk, 2002). Thus, if teachers' SEB related to EE is strengthened, their performance may improve (Özdemir, Aydın, \& Akar-Vural, 2009).

Moseley, Reinke, and Bookout (2002) noted the deficiencies of self-efficiency studies in EE. Sia (1992), who constructed the Environmental Education Efficacy Belief Instrument, concluded that pre-service teachers lack SEB related to EE. Gardner (2009) attributed this lack to the difficulty of integrating EE across the various disciplines in science education. On the other hand, Kahyaoğlu (2014) found that elementary school pre-service teachers' EE-related SEB were high and positive. In that study, the Environmental Education Selfefficacy Scale created by Özdemir et al. (2009) was used for assessment, and no other treatments were applied. In the research conducted by Moseley and her colleagues (2002), 72 pre-service teachers attended a three-day outdoor EE program. Their pre-test scores on Sia's (1992) EE Efficacy Belief Instrument were high, and their scores did not change significantly after the program, but their self-efficacy decreased after seven weeks. The researchers concluded that the more pre-service teachers learn about teaching and EE, the more concerned they become about their ability to teach EE. However, studies investigating the effect of specific features of an EE course are rarely found. This study is a contribution to the literature on this issue.

\section{Informal environmental learning and climate change education}

According to EE literature, people learn about the environment from several sources including books, exhibitions, museums, zoos, aquariums, TV, radio, magazines, Internet, and community-based organizations in addition to schools. Most environmental learning is acquired outside of school (Falk, 2005). Thus, Hofstein and Rosenfeld (1996) emphasized the importance of connecting school-based science teaching with informal settings like community-based youth programs, museums, and exhibitions. Furthermore, most researchers discovered that many in-service teachers do not feel effective when teaching EE outdoors (Ferry, 1995; Holden, Groulx, Bloom, \& Weinburgh, 2011; Simmons, 1998). Gardner (2009) noted the absence of outdoor experiences both at schools and teacher training programs. Chin (2004) also discussed the inadequacy of learning opportunities provided for pre-service teachers by out-of-school institutions such as science museums.

Informal educational settings provide opportunities for developing pro-environmental attitudes and behaviors that formal education can rarely produce (Ballantyne \& Packer, 2005). While some researchers focused on affective outcomes of exhibition visits and claimed that these visits can be motivating (Dori \& Tal, 2000; Storksdiecks, Ellenbogen, \& Heimlich, 2005), Bamberger and Tal (2008) focused on cognitive outcomes and mentioned participants' likelihood of connecting and communicating EK related to visits.

As another endeavor of this research, effect of visiting an exhibition on CC was studied. The selection of CC as a theme was intentional. Although global CC is a 
human-induced environmental problem (Intergovernmental Panel on CC, 2007), the complex structure of the problem makes it hard to be comprehended by public (Daniel, Stanisstreet, \& Boyes, 2004; Sterman \& Sweeney, 2002). Correspondingly, with its scientific and social aspects, CC is also a complex issue to teach at schools (Gardner \& Stein, 2008; Storksdieck, 2006). Studies reveal various misconceptions of students (Kılınç et.al., 2008) and even pre-service teachers about CC (Boon, 2010; Papadimitriou, 2004).

This study intends to make three contributions to EE literature. The first is a discussion on the effects of presentations and a visit to an exhibition on pre-service teachers' SEB. The second is a discussion on the effects of exhibitions on their understanding of CC and the third one is the development of an approach to teacher training in an EE course. The main purpose is to investigate any significant change in the pre-service elementary teachers' EL and SEB related to EE after taking a course featuring hands-on projects and an exhibition visit.

\section{Research questions}

The EE course lasted for 14 weeks. The study addresses three research questions:

(1) To what extent do presentations and exhibition visit embedded in an EE course have an effect on pre-service elementary teachers' EL?

(2) Do the presentations and exhibition visit have a significant effect on pre-service elementary teachers' SEB related to EE?

(3) Does the exhibition visit have any effects on the pre-service elementary teachers' understanding of CC?

\section{Method}

\section{Participants}

Fifty-eight pre-service teachers from the Elementary Education Program attended a 14week EE course at a private university in Turkey in the spring semester of 2011-2012. Fifty-eight pre-service teachers ( 8 males and 50 females) took both pre- and post-tests and participated in this study. Thirty-three of the 58 participants volunteered to visit CC exhibition. The participants were the sophomores who have limited science and environmental background. In the first year of their university education, they had science courses, namely physics, chemistry, and biology, but did not take any kind of environmental courses.

\section{Research design and procedure}

This study includes both a pre-test-post-test no control group design and descriptive analyses. Pre-service elementary teachers' pre- and post-scores of EL and SEB were analyzed by using SPSS version 21. Their pre- and post-reflections were coded by two different researchers (the authors) and determined when the complete agreement was reached. 
Table 1. Schedule of the research.

\begin{tabular}{lcc}
\hline Week & Instructional topics & Participant tasks \\
\hline 1st week & Pcological concepts & Pre-tests of SSEBTEE and SEL \\
2nd week & Pre-reflections on climate change \\
3rd-5th weeks & Ecological concepts \\
6th week & Historical development and causes of environmental problems \\
7th-11th weeks & Student presentations \\
12th week & Exhibition on climate change \\
13th week & Discussion: environmental problems and climate change \\
14th week & Post-tests of SSEBTEE and SEL post-reflections on climate change \\
\hline
\end{tabular}

The research includes two phases. At the first phase, one group pre-test-post-test design was implemented during the EE course. The second phase included an exhibition visit where two groups naturally formed as attendees and non-attendees.

Table 1 summarizes the overall schedule of the research. In the first five weeks of the EE course, the participants were informed about the basic concepts of ecology and some common environmental problems. During these weeks, mostly the instructor was active and the students have little or no control in the lessons. In the following five weeks, the participants made presentations about selected environmental problems in small groups of three or four. Each group introduced the problem and discussed the causes, consequences, and possible solutions. After each presentation, whole-class discussions took place. Then, the participants submitted individual reflections about the problem, addressing the causes, consequences, and possible solutions.

Following the presentations, the volunteer participants went to CC exhibition. Organizing the exhibition as a non-compulsory activity within the course enabled the researchers to compare the post-reflections between the visitors and non-visitors. The goal of the exhibition was to raise awareness about CC by presenting models, videos, posters, and figures. The guides assisted visitors about the models and figures. All the visitors participated in a half-hour seminar about general facts on CC. The exhibition visit took totally two hours.

At the last week of the course, the students participated in a whole-class discussion of environmental problems and CC. Hence, CC was introduced to the whole class no matter if they attended the exhibition or not.

Council on Higher Education (1998) included environmental science topics to be taught in undergraduate programs of Elementary Education Departments. Therefore, there is a compulsory EE course for two hours/week with two European Credit Transfer and Accumulation System (ECTS) credits. The aim of this course is to support pre-service elementary teachers understand ecological concepts and environmental issues; be aware about environmental issues; and have positive attitude toward environment. Basic concepts of ecology and environmental problems are involved in this course. However, this course is mostly designed and implemented in a traditional teaching method in which the instructor lectures about ecological and environmental topics. Pre-service teachers' engagement to the discussion of these topics rarely occurs. The instruction is implemented by indoor teaching and outdoor learning activities are rarely implemented. Different from the usual implementation of this course in Turkey, this study encompasses preservice elementary teachers' research, presentations, and reflections on environmental 
problems, as well as a visit to an environment-focused exhibition. Besides the aims of the EE course that are listed above, a primary goal of the course is to support them to feel confident about teaching environmental issues. For these reasons, this study is promising to bring light to research on pre-service teacher training on environmental issues.

\section{Instruments}

\section{The Scale of Environmental Literacy (SEL)}

SEL was developed by Kaplowitz and Levine (2005) and translated and adapted to Turkish by Tuncer et al. (2009). This scale has 45 items in four dimensions: EK (11 items), environmental attitudes (10 items), perception of environmental uses (19 items), and environmental concern (9 items). Cronbach alpha coefficients of the knowledge, attitudes, perception, and concern dimensions of the Turkish adaptation were found to be $.88, .64$, .80 , and .88 , respectively (Tuncer et. al., 2009).

The EK dimension evaluates knowledge of current environmental issues and composed of multiple-choice items. Each correct response gets a score of 1 while incorrect response gets 0 .

The environmental attitude dimension measures feelings and values related to environment; the environmental use dimension evaluates their willingness to participate in environmental actions; and the environmental concern dimension assesses sensitivity toward environmental problems. The items of the dimensions other than EK are composed of 5 -point Likert-type scale with a range of 5 "strongly agree" to 1 "strongly disagree".

SEL is the most appropriate instrument to evaluate pre-service elementary teachers' attitudes, perceptions, and concerns about environment as well as their knowledge about common environmental issues in a self-report measurement.

\section{The Scale of Self-Efficacy Belief Toward EE (SSEBTEE)}

The SSEBTEE was developed by Özdemir et al. (2009) to assess SEB related to EE. The SSEBTEE is a 5-point Likert-type scale including four sub-scales, which are academic competence perception (six items), responsibility perception (three items), instructive competence perception (three items), and guidance perception (three items). Academic perception dimension is related to scientific knowledge of and ability to teach environmental content. Responsibility perception dimension assesses perception of one's own responsibility to teach about environment and to let them perform environmental experiments. Instructive competence perception dimension is related to perception about their teaching to let their students be sensitive to and concerned of environmental problems. Guidance perception dimension evaluates competence to support students to be interested in environment. Cronbach alpha coefficient of the scale was found to be .76 .

This scale seems to be the best to measure pre-service elementary teachers' SEB toward EE in a self-reported way only in one semester. Pre-service elementary teachers' SEB is assumed to be changed in this relatively short time interval due to the method implemented in this study.

The participants were informed about the scales briefly before administering them and their feature of confidentiality and requirements of voluntary participation. The participants were asked to choose only one option in each item and respond to them honestly. 


\section{Reflections}

The participants wrote reflections about CC at the beginning and end of the course. They were asked to explain CC in four aspects: definition, causes, consequences, and prevention. The volunteered pre-service teachers, who attended the CC exhibition, were also asked to mention the features they found most interesting in their post-reflections. Initially, these reflections were read, and evaluated independently by the authors. Then, they decided on the selection of codes for the four aspects and determined percentages for each code. When individual assessments were compared, $85 \%$ agreement was reached. After discussion of their discrepancies, $100 \%$ agreement was reached.

\section{Results and discussion}

Data obtained from the study were evaluated by means of a $t$-test, Chi-square test, and McNemar test with .95 confidence level. According to the MedCalc (2014) manual, McNemar test is used when testing differences between paired proportions. It was used to analyze changes in categories of understanding CC before and after the treatment. In addition to statistical differences, observed differences were also recorded. Computation of effect size provided extra information about the impact or the magnitude of difference, whether small, medium, or large. It was assumed that Cohen $d$-values between .2 and .49 , .5 and .79 , and above .8 indicate small, medium, and large effect sizes, respectively (Huck, 2012). The results of the study are presented in the next section, in order of the research questions.

\section{Results related to research questions}

Research question 1: To what extent do presentations and exhibition visit embedded in an EE course have an effect on pre-service elementary teachers' EL?

Paired samples $t$-test was used to detect the effect of instruction on the participants' EL. The results indicate that their environmental attitudes and perception of environmental uses significantly increased throughout the course, while there was no significant difference between their pre- and post-test scores for EK and environmental concern (Table 2). The instructional method used seems to have positive effects on the participants' feelings and values about environment and their willingness to engage in pro-environmental behavior. However, the method did not affect their EK or sensitivity to environmental problems.

The presentations, the reflections, and the exhibition seem to have positive effects on participants' attitudes toward environment and their intentions to act environmental friendly. The reason why the method implemented has no impact on their EK and sensitivity to environmental problems may be due to the nature of the presentation topics. The

Table 2. Test results related to EL.

\begin{tabular}{lcccccc}
\hline & $t$ & $\mathrm{df}$ & Sig. & Mean difs. & Std. error mean & $d$ \\
\hline Knowledge & 0.39 & 57 & 0.70 & 0.07 & 0.17 & 0.05 \\
Attitude & 2.53 & 57 & $0.01^{*}$ & -1.41 & 0.55 & 0.32 \\
Use & 2.14 & 57 & $0.04^{*}$ & -2.28 & 1.06 & 0.31 \\
Concern & 1.78 & 57 & 0.08 & -1.10 & 0.62 & 0.17 \\
\hline${ }^{*} p<0.05$. & & & & &
\end{tabular}


presentations should have included local and/or specific environmental issues, such as pollution in a specific region, extinction of endemic species, etc. The environmental issues included in the knowledge dimension of SEL may be a good start for pre-service elementary teachers to elaborate. By searching and discussing the causes of, consequences of, and solutions for the local and/or specific problems, pre-service elementary teachers may be concerned and have knowledge about the issues they are dealing with in a deeper sense.

This study is the continuation of another research study investigating the level of the EL and SEB of the same research group (Saribas, Teksoz, \& Ertepinar, 2014). The findings of this study showed that the participants have relatively high environmental attitude, concern, and perception of environmental use although their EK and SEB are not sufficient. The sample of this study was 61 , and 3 pre-service elementary teachers withdrew the study, resulting at 58. The study presented here is continued by implementing the method described above after examining their EL and SEB at the beginning of the course.

Although the participants began with relatively high environmental attitude, concern, and perception of environmental use, their attitude and perception of use are enhanced while concern to environmental problems did not change significantly throughout the course. Their EK was not sufficient enough at the beginning of the study and they still did not improve their EK significantly throughout the course. These findings reveal that the increase in the participants' attitudes and perception of use is due to the method implemented in this study rather than the participants' level of EL and SEB at the beginning of the course.

Research question 2: Do the presentations and exhibition visit have a significant effect on pre-service elementary teachers' self-efficacy beliefs related to EE?

According to paired samples' $t$-test results, the participants' SEB increased significantly after instruction $(t 57)=-5.64, p=.01, d=.63)$. This result provides evidence for the claim that the EE course content including presentations, reflections, and exhibition visit resulted in a positive impact on pre-service elementary teachers' SEB related to EE. The participants seem to have increased their perceptions of academic and instructive competence, responsibility, and guidance for teaching environmental issues because of the presentations of and reflections on the environmental problems they researched and the exhibition visit.

Research question 3: Does the exhibition visit have any effect on pre-service elementary teachers' understanding of climate change?

Four categories and several codes related to CC emerged during analyses of the reflections (Table 3). Prominent topics mentioned in the reflections were noted and compared by groups: those who visited the exhibition and those who did not (33 attended, 25 did not). Appearances of the codes were calculated and statistically analyzed for exhibition attendees and non-attendees, as shown in Table 4.

Chi-square analysis of categories in pre-reflections showed no difference at 05 significance level between those who attended the exhibition and those who did not. In the post-reflections, it was found that the exhibition attendees were able to name more specific greenhouse gases (GHGs) $\left(\chi^{2}(1.58)=9.54, p=.01\right)$ and mentioned unplanned urbanization as a cause of CC more often than non-attendees $\left(\chi^{2}(1.58)=9.15, p=.01\right)$. Also, the exhibition attendees attributed greater importance to individual efforts when dealing with problems related to $\mathrm{CC}\left(\chi^{2}(1.58)=4.58, p=.03\right)$. The number of participants, who discussed the economic and social consequences of $\mathrm{CC}$ and did not attend the 
Table 3. Categories and codes to evaluate reflections.

\begin{tabular}{ll}
\hline Categories & \multicolumn{1}{c}{ Codes } \\
\hline Definition of climate change & Change \\
Causes of CC & Long-term \\
& Weather conditions \\
& Greenhouse gases \\
& Name of GHGs \\
& Sources of GHGs \\
& Natural causes \\
& Deforestation \\
& Industry \\
& Global warming \\
& Ozone depletion \\
& Irregular urbanization \\
Consequences of CC & Melting of glaciers \\
& Rising sea levels \\
& Global warming \\
& Droughts \\
& Floods \\
& Famine \\
Suggestions about CC & Diseases \& deaths \\
& Extinction of species \\
& Discussion about Turkey \\
& Saving energy \\
& Renewable energy \\
& Public transport \\
& Green buildings \\
& Forestation \\
& Organizations \\
Waste management \\
\hline
\end{tabular}

exhibition, was significantly higher than those who discussed the same issue and attended the exhibition $\left(\chi^{2}(1.59)=4.28, p=.04\right)$. Statistically significant McNemar test results for analyzing differences between pre- and post-reflections are presented according to the four categories related to CC.

Any appearance in participants' reflections of the definition of CC as "change in weather conditions over long periods of time" was noted and coded. The definitions were coded according to inclusion of "change," "weather conditions," and "long period of time." Table 4 shows the frequencies and percentages of these components separated by exhibition attendees and non-attendees. Significant values for the McNemar test analysis

Table 4. Comparison of pre- and post-reflections of exhibition visitors and non-visitors.

\begin{tabular}{|c|c|c|c|c|c|c|c|c|c|c|c|}
\hline \multirow[b]{3}{*}{ Category } & \multirow[b]{3}{*}{ Codes } & \multicolumn{4}{|c|}{ Exhibition visitors } & \multicolumn{5}{|c|}{ Exhibition non-visitors } & \multirow[b]{3}{*}{$p$} \\
\hline & & \multicolumn{2}{|c|}{ Pre-reflections } & \multicolumn{2}{|c|}{ Post-reflections } & \multirow[b]{2}{*}{$p$} & \multicolumn{2}{|c|}{ Pre-reflections } & \multicolumn{2}{|c|}{ Post-reflections } & \\
\hline & & $N$ & $\%$ & $N$ & $\%$ & & $N$ & $\%$ & $N$ & $\%$ & \\
\hline \multirow[t]{3}{*}{ Definition } & Change & 13 & 39.4 & 26 & 78.8 & $.01^{*}$ & 5 & 19.2 & 16 & 61.5 & $.01^{*}$ \\
\hline & Weather & 14 & 42.4 & 27 & 81.8 & $.01^{*}$ & 5 & 19.2 & 16 & 61.5 & $.01^{*}$ \\
\hline & Long period & 5 & 15.2 & 17 & 51.5 & $.01^{*}$ & 2 & 7.7 & 15 & 57.7 & $.02^{*}$ \\
\hline \multirow[t]{3}{*}{ Causes } & Greenhouse g. & 9 & 27.3 & 23 & 69.7 & $.01^{*}$ & 4 & 15.4 & 8 & 30.8 & .34 \\
\hline & Natural factors & 2 & 6.1 & 8 & 24.2 & $.03^{*}$ & 2 & 7.7 & 12 & 46.2 & .09 \\
\hline & Deforestation & 4 & 12.1 & 14 & 42.4 & $.01^{*}$ & 1 & 3.8 & 9 & 34.6 & $.02^{*}$ \\
\hline Consequences & Melting glaciers & 11 & 33.3 & 21 & 63.6 & $.04^{*}$ & 7 & 26.9 & 14 & 53.8 & .12 \\
\hline \multirow[t]{6}{*}{ Solutions } & Renewable e. & 5 & 15.2 & 20 & 60.6 & $.01^{*}$ & 2 & 7.7 & 12 & 46.2 & $.01^{*}$ \\
\hline & Forestation & 9 & 27.3 & 11 & 33.3 & .81 & 2 & 7.7 & 11 & 42.3 & $.01^{*}$ \\
\hline & Org. and gov. & 11 & 33.3 & 9 & 27.3 & .80 & 2 & 7.7 & 12 & 46.2 & $.01^{*}$ \\
\hline & Green buildings & 0 & 0 & 6 & 18.2 & $.03^{*}$ & 1 & 3.8 & 1 & 3.8 & 1.00 \\
\hline & Ind. efforts & 6 & 18.2 & 26 & 78.8 & $.01 *$ & 4 & 15.4 & 15 & 57.7 & $.01^{*}$ \\
\hline & Public transp. & 3 & 9.1 & 16 & 48.5 & $.01^{*}$ & 2 & 7.7 & 9 & 34.6 & $.04^{*}$ \\
\hline
\end{tabular}


of each component reveal an improvement in the understanding of CC for both groups (Table 4). In other words, all of the participants arrived at a better understanding of the meaning of CC by the end of the semester. The descriptive statistics on Table 4 show that the participants attributed CC mostly to GHGs in their pre- and post-reflections. They were more likely to claim that natural factors and deforestation contributed to CC in their post-reflections. McNemar analysis revealed that more participants among the exhibition attendees could name specific GHGs in their post-reflections, whereas no such improvement among non-attendees was observed. The highest number of coded topics mentioned in reflections was found in "the consequences of CC" category. Another significant issue is that some topics appeared in discussions of both causes and consequences, like global warming and deforestation, for example. McNemar analysis also revealed a significant difference between the pre- and post-reflections of exhibition attendees, many of whom added the melting of glaciers to their second discussion of consequences (Table 4).

Analysis of pre- and post-reflections showed a significant increase in the number of suggested solutions to CC, both among exhibition attendees and non-attendees. Many mentioned the need for renewable energy sources, for individual efforts, and for public transportation (Table 4). The number of attendees who suggested green buildings as a solution for CC increased significantly $(p<.05)$, whereas the number of non-attendees who mentioned forestation and the efforts of organizations, foundations, and governments increased significantly $(p<.05)$.

\section{Impressions of the climate change exhibition}

The volunteered participants, who attended the CC exhibition, were also asked to identify the features they found most interesting in their post-reflections. Table 5 gives a general picture of the most popular themes identified by the participants. The most eye-catching finding was that $75.76 \%$ of the attendees mentioned the polar bear featured in the exhibition; she had lost her habitat and was searching for food in the trash. The extinction of the polar fox was also mentioned in some of the reflections (12.12\%). 33.33\% remembered death of corals and resulting loss of habitat for aquatic life, the photograph of buildings surrounded by plants (18.18\%), and energy platforms lay on the ground to capture energy from the footsteps of people walking on the road (15.15\%). "Promising to save the environment by pressing the button" was addressed as frequently as polar fox (12.12\%). Other features of interest included a $\mathrm{CO}_{2}$ graph that shows the amount of $\mathrm{CO}_{2}$ (9.09\%); a model representing development of humankind's contribution to global warming (9.09\%); and

Table 5. Themes of interest in the exhibition.

\begin{tabular}{lc}
\hline Themes & Participants (\%) \\
\hline Polar bear & 63.64 \\
Models & 48.48 \\
Green buildings & 18.18 \\
Energy platforms & 15.15 \\
Polar fox & 12.12 \\
Recycled materials & 12.12 \\
$\mathrm{CO}_{2}$ graph & 9.09 \\
Pressing the button & 9.09 \\
Other models and photos & 33.33 \\
\hline
\end{tabular}


use of recycled materials (9.09\%). Among "other models and photos" mentioned by onethird of the attendees were an illuminated model of the Earth, $\mathrm{CO}_{2}$ in glaciers at the poles, photographs of solar panels and lightning as a source of energy. For these pre-service elementary teachers, emotionally stimulating features of the exhibition seem to have attracted more interest than intellectual themes.

\section{Insights from the reflections}

The participants were able to select any reliable written or online sources of information for their reflections. An output of this course is that the pre-reflections were based on direct and indirect quotations from several references while the post-reflections mostly included statements based on their own learning with relatively less number of references. Besides, the exhibition attendees mentioned about the exhibition when explaining facts about CC. In addition to statistical differences presented on Table 4, clear differences between pre- and post-reflections could be identified even in statements of the same participants. For instance, Participant \#9 wrote that: "Harmful gases in the atmosphere are the main cause of CC" in her pre-reflection. Then, she stated that "Greenhouse gases such as $\mathrm{CO}_{2}$, CFCs produced as a result of industrial activities constitute the main cause of CC" in her post-reflection. It was observed that more technical terms were used in the post-reflections.

Another apparent improvement in the post-reflections was identified in the solutions of CC category. Emission control and forestation are some of the popular suggestions for the solutions of CC based on the listed causes of CC in the pre-reflections. The post-reflections include more radical alternatives. For example, Participant \#42 wrote that: "I saw a green building model in the CC exhibition. In the model, solar panels placed at the roof capture energy for heating water, rainwater stored for re-use in toilets, wind tribunes at varied heights to generate electricity. Constructing green buildings would serve as a more endurable solution for CC.”

\section{Limitations}

This study has several limitations as listed below:

(1) The effects of the scores of four dimensions of SEL on each other are ignored.

(2) Peer and instructor pressure on pre-service elementary teachers' EL and SEB is neglected.

(3) Long-term effects of the intervention on EL and SEB and interrelated effects of EL and SEB are not studied.

(4) Pre-service teachers' willingness to show pro-environmental attitudes was measured in the dimension of perception of environmental use. However, investigating their environmental responsibility to put in an action is not the scope of this study.

(5) The intervention including presentations, reflections, and the visit was considered as a whole in this study and its effect on the participants' EL and SEB was examined together without investigating separately. The effect of visit was investigated only on pre-service elementary teachers' understanding of CC rather than EL and SEB. 


\section{Conclusion}

This study examined effects of an EE course on EL and SEB of pre-service elementary teachers. It revealed that their environmental attitudes, perception of environmental uses, and SEB related to EE increased significantly. Winther, Volk, and Schrock (2002) emphasized the importance of SEB in the sense that teachers need to feel adequate and contended when teaching a new subject. When the issue is about teaching environmental content, teachers become the decision-makers to include environmental content in school teaching (Yavetz, Goldman, \& Péer, 2009). Teachers' commitment to teach EE is directly related to their SEB. By taking into account the results, it could be concluded that presenting various environmental issues and their own teachings seemed to improve their SEB throughout the term.

This result is promising to shape the EE courses in Elementary Education Departments of the universities. Traditional EE courses do not include presentations, reflections, or visits. The findings of this study indicate that pre-service elementary teachers benefitted from presentations of the environmental issues that they researched, reflections on various environmental problems, and the environmental exhibition visit. The method implemented in this study seems to have a positive impact on pre-service teachers' attitudes toward environment and their intentions to engage in pro-environmental behavior as well as their SEB about teaching environmental issues. However, the methods implemented in the course did not have a significant effect on their EK as measured by the knowledge dimension of SEL, which required the application of knowledge about environmental issues in daily life. One possible reason for the underdevelopment of EK may be related to the content of the presentations. The participants presented some important facts about the assigned environmental issues. In order to acquire more knowledge about daily life situations, they should rather have engaged in real-life problem-solving tasks based on local and/or specific problems. Further studies investigating effects of engaging environmental activities may bring new light to this issue. Probably, more instructional methods such as demonstrations, micro-teachings, curriculum analyses, experiments, and hands-on outdoor activities should be included in an EE course (Ballantyne \& Packer, 2005; Dori \& Tal, 2000; Storksdiecks et al., 2005).

Analysis of the reflections showed that the participants improved their understandings of CC and its relationship with social, economic, and cultural aspects. Moreover, analysis of the reflections implied that content of the course, independent of an exhibition on CC attended by the volunteer participants, did seem to improve their ability to define CC, identify sources of GHGs and other factors that contribute to CC, and suggest possible solutions, such as renewable energy sources, recycling, and use of public transportation.

Volunteer participants seemed to benefit from visiting the CC exhibition. They were able to identify more GHGs that contribute to CC, describe unplanned urbanization as a cause, melting glaciers as a consequence, and green buildings as an alternative solution. These findings support inclusion of more visits to informal learning settings in a redesigned EE course.

It should be noted that the exhibition and EE learning within the designated class covered similar content about CC. However, the teaching strategies during class hour were different from that of the exhibition. In the exhibition, the $\mathrm{CC}$ visuals were more organized and attractive. For instance, there was a huge $\mathrm{CO}_{2}$ concentration versus average 
world temperature graph covering the whole wall at the exhibition. The time axis included figures about significant phenomena at that time period when there were sudden increases at $\mathrm{CO}_{2}$ concentration. Besides, there were dramatic figures about living things that attracted visitors' attention such as a polar bear living on a melting glacier. To sum up, the CC exhibition served as an additional learning environment for the attendees. Although the exhibit took place at a limited time period, it could be concluded that teachers and pre-service teachers can benefit from visiting subject-related exhibitions and enrich their future lessons based on the experiences gained at informal learning setting.

Another important finding revealed by analysis of the reflections is that the nonattending participants were more likely to assign responsibility for solving environmental problems to various organizations, foundations, or governments instead of seeing a role for themselves than those who attended the exhibition. Encouraging environmentally responsible behaviors is an appropriate goal for EE (Erdoğan, 2009), and the re-designed EE course should include opportunities for taking pro-environmental actions. Educational programs should enable students transfer their EK, awareness, and willingness to act for pro-environmental behavior (Dal, Alper, Özdem-Yilmaz, Öztürk, \& Sönmez, 2015). Longitudinal studies and/or action research can be useful to observe and interpret pre-service teachers' actions.

In this study, pre-service elementary teachers' environmental feelings, values, and willingness to participate in pro-environmental behavior seemed to increase as a result of presentations, reflections, and an exhibition visit. Such results were supported by Blumenfeld et al. (1991), who claimed that students' interest and perceived value would be promoted when tasks assigned to them are varied, authentic, and challenging.

The implemented EE course including the presentations, the reflections, and the exhibition visit in this study seems to foster affective learning outcomes. It is evident from qualitative analysis of the reflections about the CC exhibition that dramatic contents captured their interests more than intellectual contents. It is an important finding for EE educators to realize that an infusion of drama into a course, particularly in relation to living things, stimulates interest and memorability. However, further research is needed to examine whether this kind of stimulation contributes to EL and SEB in EE.

As Cheng and So (2015) suggested, EE is needed to be considered at two levels, namely, at pre-service teacher education level and at the society level. Pre-service teacher educators should reflect on constructing EE programs for the development of pre-service teachers' EL at teacher education level. At the society level, EE can be improved by the efforts of governmental and non-governmental organizations and the environmental business industries, supported by mass media and education programs.

\section{Implications}

The research presented here leads to several implications related to the design of EE courses in Elementary Education Departments of the universities and further researches on EE. First, EE courses need to involve pre-service teachers' presentations, reflections, and discussions on authentic, local, and specific environmental problems depending on their own research. Second, more outdoor activities, such as visits to exhibitions, natural parks, etc., should be embedded in EE courses and pre-service teachers should reflect on their experiences about these activities. Third, EE courses need to include pre-service 
teachers' own research works and reflections on various misconceptions related to environmental issues, especially about CC. Pre-service teachers should reflect their ideas based on the evidence they found in related literature. Fourth, the impact of various instructional methods such as demonstrations, micro-teachings, curriculum analyses, experiments, and hands-on outdoor activities, on pre-service teachers' EL and SEB need to be examined for bringing new light to the design of EE courses. Fifth, pre-service teachers' pro-environmental behaviors can be observed and investigated during these outdoor activities in relatively long periods rather than just examining their intentions of pro-environmental behaviors. Longitudinal studies and action research can be useful in this respect. Sixth, for future studies, forming samples with different groups of pre-service and in-service teachers might be challenging. In the event of a further research, studying with a sample composed of secondary science pre-service teachers, who would likely to have a broader environmental and scientific background from the pre-service elementary teachers would enlarge the scope of this study.

\section{Disclosure statement}

No potential conflict of interest was reported by the authors.

\section{References}

Alp, E., Ertepinar, H., Tekkaya, C., \& Yilmaz, A. (2008). A survey on Turkish elementary school students' environmental friendly behaviours and associated variables. Environmental Education Research, 14(2), 129-143.

Ballantyne, R., \& Packer, J. (2005). Promoting environmentally sustainable attitudes and behavior through free-choice learning experiences: What is the state of the game? Environmental Education Research, 11(3), 281-295.

Bamberger, Y., \& Tal, T. (2008). An experience for the lifelong journey: The long-term effect of a class visit to a science center. Visitor Studies, 11(2), 198-212.

Bandura, A. (1986). Social foundations of thought and action: A social cognitive theory. Englewood Cliffs, NJ: Prantice-Hall.

Blumenfeld, P. C., Soloway, E., Marx, R. W., Krajcik, J. S., Kuzdial, M., \& Palincsar, A. (1991). Motivation project-based learning: Sustaining the doing, supporting the learning. Educational Psychologist, 26(3\&4), 369-398.

Boon, H. J. (2010). Climate change? Who knows? A comparison of secondary students and preservice teachers. Australian Journal of Teacher Education, 35(1), 104-120.

Capra, F. (1996). Web of life - a new scientific understanding of living systems. New York, NY: Anchor Books.

Cheng, I. N. Y., \& So, W. W. M. (2015). Teachers' environmental literacy and teaching - stories of three Hong Kong primary school teachers. International Research in Geographical and Environmental Education, 24(1), 58-79.

Chin, C. (2004). Museum experience - a resource for science teacher education. International Journal of Science and Mathematics Education, 2(1), 63-90.

Council on Higher Education (http://www.che.ac.za/media_and_publications/annual-reports/ annual-report-council-higher-education-19981999).

Dal, B., Alper, U., Özdem-Yilmaz, Y., Öztürk N., \& Sönmez D. (2015). A model for pre-service teachers' climate change awareness and willingness to act for pro-climate change friendly behavior: Adaptation of awareness to climate change questionnaire. International Research in Geographical and Environmental Education, 24(3), 184-200. 
Daniel, B., Stainisstreet, M., \& Boyes, E. (2004). How can we best reduce global warming? School students' ideas and misconceptions. International Journal of Environmental Studies, 61(2), 211222.

Dori, Y. J., \& Tal, R. T. (2000). Formal and informal collaborative projects: Engaging in industry with environmental awareness. Science Education, 84(1), 95-113.

Erdoğan, M. (2009). Fifth grade students' environmental literacy and the factors affecting the students' environmentally responsible behaviors (Unpublished PhD Dissertation). Ankara: Middle East Technical University.

Erdoğan, M., Marcinkowski, T., \& Ok, A. (2009). Content analysis of selected features of K-8 environmental education research studies in Turkey, 1997-2007. Environmental Education Research, 15(5), 528-548.

Erdoğan, M., \& Ok, A. (2011). An assessment of Turkish young pupils' environmental literacy: A nationwide survey. International Journal of Science Education, 33(17), 2375-2406.

Falk, J. H. (2005). Free-choice environmental learning: Framing the discussion. Environmental Education Research, 11(3), 265-280.

Ferry, W. (1995). Enhancing environmental experiences through effective partnerships among teacher educators, field study centers, and schools. Journal of Experiential Education, 18, 133137.

Gardner, C. C. (2009). Self-efficacy in environmental education: Experiences of elementary education pre-service teachers (Unpublished $\mathrm{PhD}$ Dissertation). Columbia, SC: University of South Carolina.

Gardner, G. T., \& Stern, P. C. (2008). The short list: The most effective actions U.S. households can take to curb climate change. Philadelphia, PA: Taylor and Francis.

Hodson, D. (2003). Time for action: Science education for an alternative future. International Journal of Science Education, 25, 645-670.

Hofstein, A, \& Rosenfeld, S. (1996). Bridging the gap between formal and informal science learning. Studies in Science Education, 28, 87-112.

Holden, M. E., Groulx, J., Bloom, M. A., \& Weinburgh, M. H. (2011). Assessing teacher self-efficacy through an outdoor professional development experience. Electronic Journal of Science Education, 12(2), 1-25.

Huck. S. W. (2012). Reading statistics and research (6th ed.). Boston, MA: Allyn \& Bacon.

Intergovernmental Panel on Climate Change (2007). Climate Change 2007: Synthesis Report. In R. K. Pachauri, A. Reisinger \& the Core Writing Teams (Eds.), A contribution of Working Groups I, II, and III to the Fourth Assessment Report of the Intergovernmental Panel on Climate Change. Geneva, Switzerland.

Kahyaoğlu, M. (2014). The research of relationship between environmentally aware prospective teachers' qualities and self-efficacy beliefs towards environmental education. Procedia- Social and Behavioral Sciences, 116, 4493-4497.

Kaplowitz, M.D., \& Levine, R. 2005. How environmental knowledge measures up at a big ten university. Environmental Education Research 11, 143-160.

Kılınç, A., Stanisstreet, M., \& Boyes, E. (2008). Turkish students' ideas about global warming. International Journal of Environmental and Science Education, 3(2), 89-98.

MedCalc. (http://www.medcalc.org/manual/mcnemar_test.php)

Moseley, C., Reinke, K., \& Bookout, V. (2002). The effect of teaching outdoor environmental education on preservice teachers' attitudes toward self-efficacy and outcome expectancy. The Journal of Environmental Education, 34(1), 9-15.

Özdem, Y., Dal, B., Öztürk, N., Sönmez, D., \& Alper, U. (2014). What is that thing called climate change? An investigation into the understanding of climate change by seventh-grade students. International Research in Geographical and Environmental Education, 23(4), 294-313.

Özdemir, A., Aydin, N., \& Akar-Vural, R. (2009). A scale development study on self-efficacy beliefs through environmental education. Dokuz Eylül University Buca Education Faculty Journal, 26, $1-8$. 
Papadimitriou, V. (2004). Prospective primary teachers' understanding of climate change, greenhouse effect, and ozone layer depletion. Journal of Science Education and Technology, 13(2), 299-307.

Petegem, P. V., Blieck, A., Imbrecht, I., \& Hout, T. V. (2005). Implementing environmental education in pre-service teacher training. Environmental Education Research, 11(2), 161-171.

Pintrich, P. R., \& Schunk, D. H. (2002). Social cognitive theory. In J. W. Johnston \& K. M. Davis (Eds.), Motivation in education: Theory, research and applications (pp. 141-189). Columbus, $\mathrm{OH}$ : Merrill Prentice Hall.

Roth, C. E. (1992). Environmental literacy: Its roots, evolution and direction in the 1990s. Columbus, OH: ERIC/CSMEE.

Saribas, D., Teksoz, G., \& Ertepinar, H. (2014). The relationship between environmental literacy and self-efficacy beliefs toward environmental education. Procedia - Social and Behavioral Sciences, 116(2), 3664-3668.

Sia, A. P. (1992). Preservice elementary teachers' perceived efficacy in teaching environmental education: A preliminary study. Paper presented at the annual meeting of the North American Association for Environmental Education, Toronto.

Simmons, D. (1998). Using natural settings for environmental education: Perceived benefits and barriers. Journal of Environmental Education, 29, 23-31.

Sterman, J. D., \& Sweeney, L. B. (2002). Cloudy skies: Assessing public understanding of global warming. Systems Dynamics Review, 18(2), 207-240.

Storksdieck, M. (2006). Field trips in environmental education. Berlin: Berliner WissenschaftsVerlag.

Storksdiecks, M., Ellenbogen, K., \& Heimlich, J. E. (2005). Changing minds? Reassessing outcomes in free-choice environmental education. Environmental Education Research, 11(3), 353-369.

Tuncer, G., Tekkaya, C., Sungur, S., Cakiroglu, J., Ertepinar, H., \& Kaplowitz, M. (2009). Assessing pre-service teachers' environmental literacy in Turkey as a mean to develop teacher education programs. International Journal of Educational Development, 29, 426-436.

UNESCO-UNEP. (1987). The Tbilisi Declaration: Final report intergovernmental conference on environmental education. Organized by UNESCO with UNEP, Tbilisi, USSR, 14-26 October, 1977. Paris: Author.

West, S. E. (2015). Understanding participant and practitioner outcomes of environmental education. Environmental Education Research, 21(1), 45-60.

Winther, A. A., Volk, T. L., \& Schrock, S. A. (2002). Teacher decision-making in the first year of implementation an issues-based environmental education program: A qualitative study. Journal of Environmental Education, 33(3), 27-33.

Yavetz, B., Goldman, D., \& Péer, S. (2009). How do preservice teachers perceive 'environment' and its relevance to their area of teaching? Environmental Education Research, 15(4), 1-17. 